\title{
Seismic stability analysis of rock slopes by yield design theory using the generalized Hoek-Brown criterion
}

\author{
Mounir Belghali ${ }^{1,2}$ and Zied Saada ${ }^{1}$ \\ ${ }^{1}$ Université de Tunis El Manar, Ecole Nationale d'Ingénieurs de Tunis, Labo. de Génie Civil (LGC-ENIT), Tunis, Tunisie. \\ ${ }^{2}$ Direction Générale des Études Technologiques, Institut Supérieur des Études Technologiques de Radès, Radès, Tunisie.
}

\begin{abstract}
The stability of rock slope is studied using the kinematic approach of yield design theory, under the condition of plane strain and by considering the last version of the Hoek-Brown failure criterion. This criterion, which is suitable to intact rock or rock mass highly fractured regarded as isotropic and homogeneous, is widely accepted by the rock mechanics community and has been applied in numerous projects around the world. The failure mechanism used to implement the kinematic approach is a log-spiral rotational mechanism. The stability analysis is carried out under the effects of gravity forces and a surcharge applied along the upper plateau of the slope. To take account of the effects of forces developed in the rock mass during the passage of a seismic wave, the conventional pseudo-static method is adopted. This method is often used in slope stability study for its simplicity and efficiency to simulate the seismic forces. The results found are compared with published numerical solutions obtained from other approaches. The comparison showed that the results are almost equal. The maximum error found is less than $1 \%$, indicating that this approach is effective for analyzing the stability of rock slopes. The relevance of the approach demonstrated, investigations are undertaken to study the influence of some parameters on the stability of the slope. These parameters relate to the mechanical strength of the rock, slope geometry and loading.
\end{abstract}

\section{Introduction}

Analysis of the rock slope stability was often carried out using the limit equilibrium method and considering the Mohr-Coulomb failure criterion. The success of this approach is mainly due to its simplicity. However, because of the arbitrary simplifying assumptions on which it is based, the solution provided by limit equilibrium method is considered not rigorous in a strict mechanical sense. To avoid this, many researchers have used other methods, particularly the limit analysis method [1-5]. In addition, several works have shown the weakness of the Mohr-Coulomb criterion to adequately describe the resistance of rocks [6-8]. A variety of nonlinear criteria were then proposed in the literature [915]. The most practical criterion that has attracted the attention of rock mechanics community is the HoekBown criterion [16]. As soon as it was published in 1980, this empirical criterion has been intensely used and has undergone several improvements in order to correctly evaluate the resistance of different types of rocks. This criterion is applicable for intact rocks and for strongly fractured rock masses, which are assumed to be isotropic [17].

The non-linearity of a failure criterion greatly complicates the study of slope stability, in particular when the limit analysis method is used. To solve this problem, Zhang and Chen [15] proposed a numerical method, which they called the inverse method. Other researchers have proposed methods based on a technique called the tangential technique [18]. Collins et al [18] generalized the work of Chen [1] on the stability of slopes which material's resistance is governed by a linear failure criterion to the case of nonlinear materials. Instead of using Hoek-Brown's original criterion to evaluate the stability factor, they used a tangent Mohr-Coulomb criterion, characterized by a friction angle $\varphi_{t}$ and cohesion $\mathrm{c}_{\mathrm{t}}$, and proposed the following expression of the stability factor: $\mathrm{N}_{\mathrm{n}}=\mathrm{N}_{\mathrm{L}} \cdot \mathrm{c}_{\mathrm{t}} /\left(\mathrm{s}^{0.5} \cdot \sigma_{\mathrm{c}}\right)$. In this expression $\mathrm{N}_{\mathrm{L}}=\gamma \cdot \mathrm{H}_{\mathrm{c}} / \mathrm{c}_{\mathrm{t}}$ is the linear stability factor previously calculated by Chen [1]. At the same period, Drescher and Christopoulos [19] proposed a similar technique for the general nonlinear criterion proposed by Zhang and Chen [15]. Yang et al [20,21] extended the work of Collins et al [18] to the case of materials obeying the Hoek-Brown criterion and proposed the "generalized tangential technique". In their work, the stability factor is calculated from the critical height obtained using the upper bound limit analysis $\mathrm{N}_{\mathrm{n}}=\gamma \cdot \mathrm{H}_{\mathrm{c}} /\left(\mathrm{s}^{0.5} \cdot \sigma_{\mathrm{c}}\right)$. Unlike Collins et al. [18], Yang et al. [20,21] do not use the linear stability factor previously calculated by Chen [1].

Earthquakes are one of the sources of slope instability. They can generate destabilizing and cyclical 
inertia forces or a reduction in shear strength. If these two effects are combined, they induce an overall decrease in the stability of the slope affected by the earthquake. Therefore, it is very important to carry out an assessment of the seismic slope stability. Several methods are available to perform this type of study; the simplest is the pseudo-static method. This approach is widely accepted as a means to assess the seismic slope stability [22-25]. To simulate the potential inertia forces due to ground accelerations in an earthquake, horizontal and vertical static seismic forces are introduced. These forces are assumed to be proportional to the applied forces times horizontal and vertical average seismic coefficients $K_{h}$ and $\mathrm{K}_{\mathrm{v}}[26]$.

This work deals with the study of the static and seismic stability of homogeneous isotropic rock slope obeying the most recent version of the Hoek-Brown failure criterion [27] and using the kinematic approach of yield design theory. This method constitutes a generalization of the limit analysis [28-30]. It is distinguished by taking into account a failure criterion representing the limitation of the stresses and disregards all other information relating to the model of plastic behavior of the material, in particular its flow rule. To carry out the seismic analysis, the shear strength is assumed to be unaffected by the earthquake and the generated inertial forces are simulated using the pseudostatic approach. Only the coefficient $K_{h}$ is taken into account, the coefficient $\mathrm{K}_{\mathrm{v}}$ is neglected. This hypothesis has been adopted by several researchers [22-25]. What distinguishes this work is the direct use, in calculations, of the Hoek-Brown failure criterion. In fact, this will properly reflect the non-linearity of the criterion.

\section{Problem description}

\subsection{Geometry and loading}

The slope studied has a height $\mathrm{H}$ and two inclinations $\beta$ and $\alpha$ "figure 1 ". $\beta$ is the main inclination belonging to the interval ]0, $\pi / 2$ ] and $\alpha$ is the inclination of the upper plateau, strictly lower than $\beta$. The slope is subjected to gravitational forces $\gamma \underline{e}_{1}$, a uniformly distributed surcharge $\mathrm{qe}_{1}$ applied along the upper plateau and seismic inertial forces. The geometry of the slope and the loading are assumed to be invariable in the direction $\underline{\mathrm{e}}_{3}$. Therefore, the problem is considered to be a plane strain problem.

\subsection{Generalized Hoek-Brown Criterion}

The material constituting the slope is considered to be homogeneous and isotropic obeying the generalized Howk-Brown nonlinear failure criterion. By adopting the convention of the positive stress in tension, this criterion is written in the following form:

$\mathrm{f}(\underline{\underline{\sigma}})=\sigma_{1}-\sigma_{3}-\sigma_{\mathrm{c}}\left(-\mathrm{m} \cdot \sigma_{1} / \sigma_{\mathrm{c}}+\mathrm{s}\right)^{\mathrm{n}} \leq 0$

where $\sigma_{1}$ and $\sigma_{3}$ are the principal stresses respectively major and minor, $\sigma_{c}$ is the uniaxial compressive strength of the intact rock. The parameters of the criterion: $\mathrm{m}, \mathrm{s}$ and $\mathrm{n}$ depend on the geological strength index (GSI) as follows:

$\mathrm{m}=\mathrm{m}_{\mathrm{i}} \exp \left(\frac{\mathrm{GSI}-100}{28-14 \mathrm{D}}\right)$

$\mathrm{S}=\exp \left(\frac{\mathrm{GSI}-100}{9-3 \mathrm{D}}\right)$

$\mathrm{n}=\frac{1}{2}+\frac{1}{6}\left[\exp \left(-\frac{\mathrm{GSI}}{15}\right)-\exp \left(-\frac{-20}{3}\right)\right]$

Where $\mathrm{m}_{\mathrm{i}}$ is the value of parameter $\mathrm{m}$ for intact rock. For some typical rocks, Hoek [31] provides approximate values of this parameter. $\mathrm{D}$ is a disturbance coefficient that varies from 0.0 for the undisturbed in situ rock masses to 1.0 for very disturbed rock masses.

\section{Implementation of the kinematic approach of yield design theory}

\subsection{Kinematic approach}

According to the kinematic approach of the yield design, the slope is stable under the external loading if for any kinematically admissible virtual velocity field $\underline{U}$ (termed failure mechanism in the sequel), defined in the plane $\left(\underline{\mathrm{e}}_{1}, \underline{\mathrm{e}}_{2}\right)$, the work of the external loading $\mathrm{P}_{\mathrm{e}}(\underline{\mathrm{U}})$ and the maximum resisting work $\mathrm{P}_{\mathrm{mr}}(\underline{\mathrm{U}})$ in this velocity field satisfy the following inequality [29,30]:

$\forall \underline{\mathrm{U}}$ K.A. $\quad \mathrm{P}_{\mathrm{e}}(\underline{\mathrm{U}}) \leq \mathrm{P}_{\mathrm{mr}}(\underline{\mathrm{U}})$

The expression of the work of external loading in a kinematically admissible virtual velocity field is:

$$
\begin{aligned}
\mathrm{P}_{\mathrm{e}}(\underline{\mathrm{U}})= & \int_{\mathrm{V}} \gamma \cdot \underline{\mathrm{e}}_{1} \cdot \underline{\mathrm{U}} \cdot \mathrm{dV}+\int_{\partial V_{q}} \mathrm{q} \cdot \underline{\mathrm{e}}_{1} \cdot \underline{\mathrm{U}} \cdot \mathrm{dS}+ \\
& \mathrm{K}_{\mathrm{h}}\left(\int_{\mathrm{V}} \gamma \cdot \underline{\mathrm{e}}_{2} \cdot \underline{\mathrm{U}} \cdot \mathrm{dV}+\int_{\partial V_{q}} \mathrm{q} \cdot \underline{\mathrm{e}}_{2} \cdot \underline{\mathrm{U}} \cdot \mathrm{dS}\right)
\end{aligned}
$$

In this expression, $\mathrm{V}$ is the volume of the rock mass and $\partial \mathrm{V}_{\mathrm{q}}$ is the contour of $\mathrm{V}$ on which $\mathrm{q}$ is applied.

The maximum resisting work is given by:

$\mathrm{P}_{\mathrm{mr}}(\underline{\mathrm{U}})=\int_{\mathrm{V}} \pi(\underline{\mathrm{d}}) \mathrm{dV}+\int_{\Sigma} \pi(\underline{v}, \llbracket \underline{\mathrm{U}} \rrbracket) \mathrm{d} \Sigma$

Where $\underline{\underline{\mathrm{d}}}$ is the strain rate field associated with $\underline{\mathrm{U}}$;

$\llbracket \underline{U} \rrbracket$ is the jump of $\underline{U}$ when crossing a possible velocity discontinuity surface $\bar{\Sigma}$ following its normal $\underline{v}$.

The $\Pi$-functions are defined by

$\pi(\underline{\underline{d}})=\sup _{\underline{\underline{\sigma}}}\{\underline{\underline{\sigma}}: \underline{\underline{\mathrm{d}}} ; \mathrm{f}(\underline{\underline{\sigma}}) \leq 0\}$

$\pi(\underline{v}, \llbracket \underline{U} \rrbracket)=\sup _{\underline{\underline{\sigma}}}\{(\underline{\underline{\sigma}} \cdot \underline{v}) \cdot \llbracket \underline{\mathrm{U}} \rrbracket ; \mathrm{f}(\underline{\sigma}) \leq 0\}$

The $\Pi$-functions for a Hoek-Brown failure criterion are given in [32].

The safety factor is defined as:

$\Gamma=\mathrm{P}_{\mathrm{mr}}(\underline{\mathrm{U}}) / \mathrm{P}_{\mathrm{e}}(\underline{\mathrm{U}})$ 
A necessary condition of stability is that:

$\Gamma \geq 1$

It should be noted that this condition of stability requires that the work of the external loading is strictly positive.

The safety factor introduced in the present approach is completely equivalent to the safety factor traditionally defined as the ratio between maximum and mobilized shear stresses. Both can be used to characterize slope stability $[29,33]$.

\subsection{Failure mechanism}

The failure mechanism selected is a rotational mechanism "figure 1" which has been widely used in the analysis of homogeneous slopes obeying a Mohr-Coulomb failure criterion. It defines two volumes, the first one is rotating about the center $\Omega$ with an angular velocity $\omega$ and the other one is kept motionless. The curve $\mathrm{I}_{1} \mathrm{I}_{2}$ separating the two volumes is a log-spiral arc of angle $\varphi$ and focus $\Omega$ defined by the equation $r(\theta)=r_{0} \mathrm{e}^{\left(\theta-\theta_{1}\right) \tan \varphi}$ in a polar coordinate system $(\Omega, \mathrm{r}, \theta) . \mathrm{r}_{0}=\Omega \mathrm{I}_{1}$ is the radius of the log-spiral curve for $\theta=\theta_{1}$.

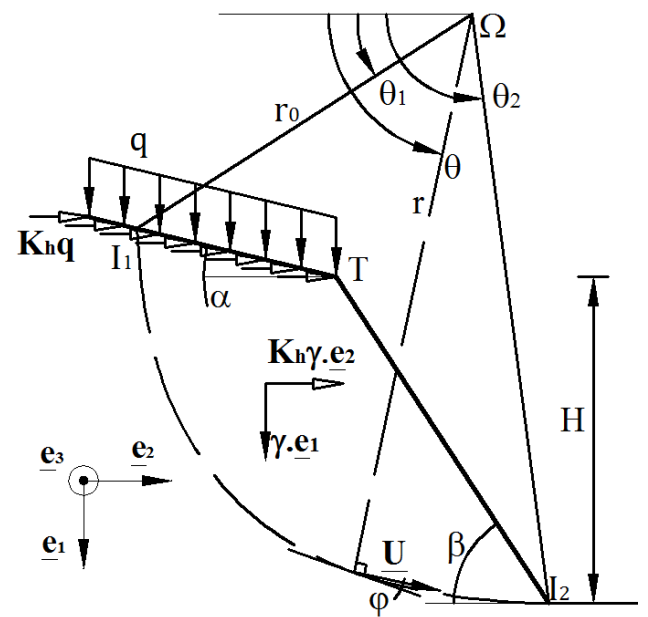

Fig. 1. Loading and slope failure mechanism

Consequently, the discontinuity of velocity at any point of this line is inclined at an angle $\varphi$ with respect to the tangent to the same point. As shown in "figure 1", the logarithmic spiral curve starts from the upper plateau and passes through the slope toe. Therefore, this spiral arc is completely defined by the three independent parameters: $\theta_{1}, \theta_{2}$ and $\varphi$.

\subsection{Safety factor}

The slope is subjected to self weight, surcharge and seismic forces. Taking into account the failure mechanism described in the previous section the work of the external forces is:

$P_{e}(\underline{U})=r_{0}^{3} \cdot \gamma \cdot \omega \cdot\left[\left(f_{0}-f_{1}-f_{2}\right)+K_{h} \cdot\left(f_{0}^{s}-f_{1}^{s}-f_{2}^{s}\right)\right]+$ $\mathrm{r}_{0}^{2} \cdot \mathrm{q} \cdot \omega\left[\mathrm{f}_{3}+K_{h} \cdot \mathrm{f}_{3}^{\mathrm{s}}\right]$

(12)

In this expression $\mathrm{f}_{0}, \mathrm{f}_{1}, \mathrm{f}_{2}, \mathrm{f}_{3}, \mathrm{f}_{0}^{\mathrm{s}}, \mathrm{f}_{1}^{\mathrm{s}}, \mathrm{f}_{2}^{\mathrm{s}}$ and $\mathrm{f}_{3}^{\mathrm{s}}$ are dimensionless functions of the parameters $\theta_{1}, \theta_{2}$ and $\varphi$ defined by the expressions below: $\mathrm{f}_{0}=\frac{\mathrm{e}^{3\left(\theta_{2}-\theta_{1}\right) \tan \varphi}\left(3 \cos \theta_{2} \tan \varphi+\sin \theta_{2}\right)-\left(3 \cos \theta_{1} \tan \varphi+\sin \theta_{1}\right)}{3\left(9 \tan ^{2} \varphi+1\right)}$

$\mathrm{f}_{1}=\mathrm{D} \frac{\sin \left(\theta_{1}+\alpha\right)}{6}\left[\cos \theta_{1}+\mathrm{X}_{2}^{\Omega}\right]$

$\mathrm{f}_{2}=\mathrm{H} \frac{\sin \left(\theta_{2}+\beta\right)}{6 \cdot \sin \beta} \cdot \mathrm{e}^{\left(\theta_{2}-\theta_{1}\right) \tan \varphi}\left[\cos \theta_{2} \mathrm{e}^{\left(\theta_{2}-\theta_{1}\right) \tan \varphi}+\mathrm{X}_{2}^{\Omega}\right]$

$\mathrm{f}_{3}=\frac{1}{2} \mathrm{D} \cdot\left[\cos \theta_{1}+\mathrm{X}_{2}^{\Omega}\right]$

$\mathrm{f}_{0}^{\mathrm{S}}=\frac{\mathrm{e}^{3\left(\theta_{2}-\theta_{1}\right) \tan \varphi}\left(3 \sin \theta_{2} \tan \varphi-\cos \theta_{2}\right)-\left(3 \sin \theta_{1} \tan \varphi-\cos \theta_{1}\right)}{3\left(9 \tan ^{2} \varphi+1\right)}$

$\mathrm{f}_{1}^{\mathrm{s}}=\mathrm{D} \frac{\sin \left(\theta_{1}+\alpha\right)}{6}\left[\sin \theta_{1}-\mathrm{X}_{1}^{\Omega}\right]$

$\mathrm{f}_{2}^{\mathrm{s}}=\mathrm{H} \frac{\sin \left(\theta_{2}+\beta\right)}{6 \cdot \sin \beta} \cdot \mathrm{e}^{\left(\theta_{2}-\theta_{1}\right) \tan \varphi}\left[\sin \theta_{2} \mathrm{e}^{\left(\theta_{2}-\theta_{1}\right) \tan \varphi}-\mathrm{X}_{1}^{\Omega}\right]$

$\mathrm{f}_{3}^{\mathrm{s}}=\frac{1}{2} \mathrm{D} \cdot\left[\sin \theta_{1}-\mathrm{X}_{1}^{\Omega}\right]$

In these expressions:

$\mathrm{D}=\mathrm{TI}_{1} / \mathrm{r}_{0}=\frac{\sin \left(\theta_{1}+\beta\right)-\mathrm{e}^{\left(\theta_{2}-\theta_{1}\right) \tan \varphi} \cdot \sin \left(\theta_{2}+\beta\right)}{\sin (\beta-\alpha)}$

$\mathrm{H}=\mathrm{H} / \mathrm{r}_{0}=\mathrm{e}^{\left(\theta_{2}-\theta_{1}\right) \tan \varphi} \cdot \sin \theta_{2}-\sin \theta_{1}-\mathrm{D} \sin \alpha$

$\mathrm{X}_{1}^{\Omega}=\mathrm{X}_{1}^{\Omega} / \mathrm{r}_{0}=-\sin \theta_{1}-\mathrm{D} \cdot \sin \alpha$

$\mathrm{X}_{2}^{\Omega}=\mathrm{X}_{2}^{\Omega} / \mathrm{r}_{0}=\cos \theta_{1}$-D. $\cos \alpha$

$\mathrm{X}_{1}^{\Omega}$ and $\mathrm{X}_{2}^{\Omega}$ are the coordinates of the center of rotation $\Omega$.

According to the mechanism adopted, the virtual deformation rate $\underline{\underline{d}}$ is zero. In addition, the velocity discontinuity occurs along the $\operatorname{arc} \mathrm{I}_{1} \mathrm{I}_{2}$ of the spiral, then (7) is written as follows:

$\mathrm{P}_{\mathrm{mr}}=\int_{\mathrm{I}_{1} \mathrm{I}_{2}} \pi(\underline{v}, \llbracket \underline{\mathrm{U}} \rrbracket) \mathrm{d} \Sigma$

The maximum resisting work is then:

$\mathrm{P}_{\mathrm{mr}}=\mathrm{r}_{0}^{2} \cdot \sigma_{\mathrm{c}} \omega \cdot \mathrm{f}_{4}$

The expression of the dimensionless function $\mathrm{f}_{4}$ is:

$\mathrm{f}_{4}=\frac{1}{2}\left[\frac{\mathrm{s}}{\mathrm{m}}+\mathrm{m}^{\frac{\mathrm{n}}{1-\mathrm{n}}}\left(\mathrm{n}^{\frac{\mathrm{n}}{1-\mathrm{n}}}-\mathrm{n}^{\frac{1}{1-\mathrm{n}}}\right)\left(\frac{1-\sin \varphi}{2 \sin \varphi}\right)^{\frac{1}{1-\mathrm{n}}}\right] \cdot\left(\mathrm{e}^{2\left(\theta_{2}-\theta_{1}\right) \tan \varphi}-1\right)$

Taking account of (10), (12) and (26) the safety factor is:

$\Gamma=\frac{\mathrm{f}_{4} \cdot \mathrm{H}}{\frac{\gamma \mathrm{H}}{\sigma_{\mathrm{c}}} \cdot\left[\left(\mathrm{f}_{0}-\mathrm{f}_{1}-\mathrm{f}_{2}\right)+\mathrm{K}_{\mathrm{h}} \cdot\left(\mathrm{f}_{0}^{\mathrm{s}}-\mathrm{f}_{1}^{\mathrm{s}}-\mathrm{f}_{2}^{\mathrm{s}}\right)\right]+\frac{\mathrm{q}}{\sigma_{\mathrm{c}}} \cdot \mathrm{H} \cdot\left[\mathrm{f}_{3}+\mathrm{K}_{\mathrm{h}} \mathrm{f}_{3}^{\mathrm{s}}\right]}$

$\Gamma$ is therefore a function of the parameters: $\beta, \alpha$, $\gamma \mathrm{H} / \sigma \mathrm{c}, \mathrm{q} / \sigma \mathrm{c}, \mathrm{mi}, \mathrm{GSI}$ and $\mathrm{D}$. These parameters are related to slope inclination, gravity level, surcharge and rock strength parameters.

The critical value of the safety factor is obtained by minimization of the objective function $\Gamma$ with respect to the set of variables $\theta_{1}, \theta_{2}$ and $\varphi$ taking into account the following constraints: 


$$
\left\{\begin{array}{l}
0<\varphi<\pi / 2 \\
0<\theta_{1}<\theta_{2}<\pi-\beta \\
\sin \left(\beta+\theta_{1}\right)-\mathrm{e}^{\left(\theta_{2}-\theta_{1}\right) \tan \varphi} \cdot \sin \left(\beta+\theta_{2}\right)>0 \\
r_{0}>0
\end{array}\right.
$$

\section{Numerical results}

\subsection{Comparisons}

The validation of the approach presented in this work is carried out using the results published by Yang et al [21]. These authors used the same version of the Hoek-Brown criterion. It should be recalled that in [21] the stability of the slope is characterized by a stability factor calculated from the critical height. Whereas, here, a safety factor that plays this role. Equivalence between these two factors is therefore necessary to make comparisons. It is obvious that if the slope height is critical then $\Gamma=1$. In this situation, in the absence of surcharge and taking into account the expression of the stability factor, equation (28) gives:

$N_{n}=\frac{f_{4} \cdot H}{s^{0.5} \cdot\left[\left(f_{0}-f_{1}-f_{2}\right)+K_{h} \cdot\left(f_{0}^{s}-f_{1}^{s}-f_{2}^{s}\right)\right]}$

The minimization of (30) with respect to $\theta_{1}, \theta_{2}$ and $\varphi$ and taking account of the conditions (29) gives $\mathrm{N}_{\mathrm{n}}$.

Table 1. Comparison of stability factors

\begin{tabular}{c|ccc}
$\beta(\mathrm{deg})$ & $\mathrm{N}_{\mathrm{n}}$ Present Work & $\mathrm{N}_{\mathrm{n}}[21]$ & Relative diff. (\%) \\
\hline 50 & 11,56 & 11,55 & $-0,09$ \\
60 & 6,53 & 6,52 & $-0,15$ \\
70 & 3,79 & 3,76 & $-0,80$ \\
80 & 2,28 & 2,27 & $-0,44$ \\
90 & 1,41 & 1,41 & 0,00 \\
\hline
\end{tabular}

$\left(\alpha=0, \mathrm{q}=0, \mathrm{GSI}=50, \mathrm{mi}=7, \mathrm{D}=0\right.$ and $\left.\mathrm{K}_{\mathrm{h}}=0.1\right)$

Finally, to validate this approach, the calculation of a safety factor is transformed into a calculation of a stability factor by stipulating that the height of the slope is critical. Table 1 illustrates a comparison between the numerical results obtained from the minimization of (30) and those published in [21] in the case where $m_{i}=7$. The small relative errors obtained show the effectiveness of the approach described in this paper.

\subsection{Effects of parameters $\alpha$ and $q / \sigma_{c}$}

In order to study the effect of the inclination $\alpha$, the safety factor was evaluated in the absence of seismic forces and surcharge considering the following parameters: $\gamma \mathrm{H} / \sigma \mathrm{c}=0.02, \mathrm{GSI}=40, \mathrm{D}=0$ and $\mathrm{mi}=7 . \alpha$ varies from 0 to $20^{\circ}$. The results obtained are illustrated in Table 2. Examination of these results clearly shows that the effect of the inclination $\alpha$ on the safety factor is insignificant.

The effect of the surcharge was also studied in the following configuration: $\gamma \mathrm{H} / \sigma_{\mathrm{c}}=0.02, \quad \mathrm{GSI}=40, \mathrm{~m}_{\mathrm{i}}=7$, $\mathrm{D}=0, \mathrm{~K}_{\mathrm{h}}=0$ and $\alpha=0$. Table 3 gives the values of the safety factor when $\beta$ varies from 50 to $90^{\circ}$ and the loading parameter $\mathrm{q} / \sigma_{\mathrm{c}}$ varies from 0 to $2.10^{-3}$. From Table 3, it is found that the surcharge has a small effect on the safety factor.

\begin{tabular}{c|ccccc}
\multirow{5}{*}{$\begin{array}{c}\text { Table 2. Variation of } \Gamma \text { as a function of } \alpha \\
(\mathrm{deg})\end{array}$} & 0 & 5 & 10 & 15 & 20 \\
\cline { 2 - 6 }$\alpha(\mathrm{deg})$ \\
\hline 50 & 36,14 & 35,98 & 35,96 & 35,55 & 35,16 \\
60 & 19,37 & 19,31 & 19,28 & 19,18 & 19,01 \\
70 & 10,27 & 10,23 & 10,19 & 10,11 & 10,07 \\
80 & 5,60 & 5,58 & 5,57 & 5,51 & 5,52 \\
90 & 3,20 & 3,19 & 3,18 & 3,16 & 3,15 \\
\hline
\end{tabular}

\begin{tabular}{|c|c|c|c|c|c|}
\hline \multirow{2}{*}{$\begin{array}{c}\beta \\
\text { (deg) }\end{array}$} & \multicolumn{5}{|c|}{$\mathrm{q} / \sigma_{\mathrm{c}} \times 10^{3}$} \\
\hline & 0 & 0,5 & 1 & 1,5 & 2 \\
\hline 50 & 36,14 & 34,70 & 33,36 & 32,06 & 30,81 \\
\hline 60 & 19,37 & 18,64 & 17,90 & 17,22 & 16,54 \\
\hline 70 & 10,27 & 9,87 & 9,49 & 9,12 & 8,76 \\
\hline 80 & 5,60 & 5,38 & 5,16 & 4,96 & 4,77 \\
\hline 90 & 3,20 & 3,06 & 2,93 & 2,81 & 2,70 \\
\hline
\end{tabular}

\subsection{Effect of gravity level}

To illustrate the impact of the gravity level $\gamma \mathrm{H} / \sigma_{\mathrm{c}}$ on the safety factor, a study is carried in the absence of surcharge and in the case of undisturbed in situ rock $D=0$ having the following strength parameters: GSI $=50$ and $\mathrm{m}_{\mathrm{i}}=10$. The inclination $\beta$ is varying from 50 to $90^{\circ}$. The obtained results are shown in "figure 2 ". As expected, $\Gamma$ is a decreasing function of $\gamma \mathrm{H} / \sigma_{\mathrm{c}}$. The decrease in $\Gamma$ is greater when the slope inclination decreases.

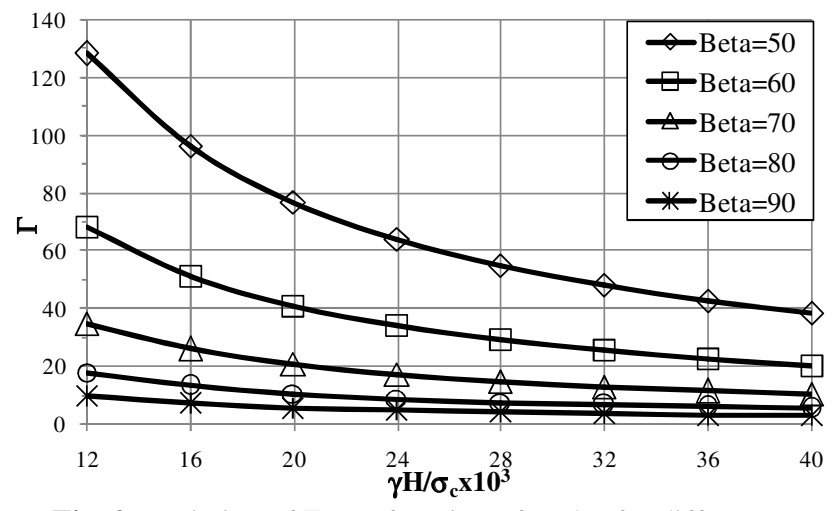

Fig. 2. Variation of $\Gamma$ as a function of $\gamma \mathrm{H} / \sigma_{\mathrm{c}}$ for different inclination of the slope $\left(\alpha=0\right.$ and $\left.K_{h}=0\right)$

\subsection{Effects of rock strength parameters}

This section presents numerical simulations carried out in order to give, in a particular configuration, some preliminary ideas on the individual impact of slope inclination and strength properties on the safety factor. These simulations are performed for three rock types in the following situation: $\gamma \mathrm{H} / \sigma_{\mathrm{c}}=0.02 \alpha=0, \mathrm{q}=0$ and $\mathrm{D}=0$. The obtained results are presented in Table 4. 


\begin{tabular}{|c|c|c|c|c|c|c|c|c|c|c|c|c|c|}
\hline \multirow[b]{2}{*}{$\mathrm{K}_{\mathrm{h}}$} & \multirow[b]{2}{*}{$\beta$} & \multicolumn{3}{|c|}{ GSI $=20$} & \multicolumn{3}{|c|}{$\mathrm{GSI}=40$} & \multicolumn{3}{|c|}{$\mathrm{GSI}=60$} & \multicolumn{3}{|c|}{$\mathrm{GSI}=80$} \\
\hline & & $\mathrm{mi}=7$ & $\mathrm{mi}=10$ & $\mathrm{mi}=15$ & $\mathrm{mi}=7$ & $\mathrm{mi}=10$ & $\mathrm{mi}=15$ & $\mathrm{mi}=7$ & $\mathrm{mi}=10$ & $\mathrm{mi}=15$ & $\mathrm{mi}=7$ & $\mathrm{mi}=10$ & $\mathrm{mi}=15$ \\
\hline \multirow{5}{*}{0} & 50 & 11,99 & 18,05 & 29,01 & 36,14 & 51,53 & 77,99 & 81,80 & 113,08 & 167,01 & 178,96 & 242,51 & 348,90 \\
\hline & 60 & 5,82 & 8,41 & 13,19 & 19,37 & 26,58 & 39,20 & 46,83 & 61,68 & 87,64 & 110,93 & 140,00 & 190,85 \\
\hline & 70 & 2,78 & 3,61 & 5,18 & 10,27 & 12,84 & 17,42 & 27,13 & 33,04 & 42,64 & 70,37 & 81,92 & 102,24 \\
\hline & 80 & 1,41 & 1,58 & 1,88 & 5,60 & 6,18 & 7,21 & 16,55 & 18,13 & 20,35 & 46,80 & 50,40 & 55,96 \\
\hline & 90 & 0,77 & 0,77 & 0,77 & 3,20 & 3,20 & 3,20 & 10,35 & 10,35 & 10,35 & 31,78 & 31,80 & 31,80 \\
\hline \multirow{5}{*}{0,1} & 50 & 7,33 & 10,86 & 17,25 & 23,31 & 32,66 & 48,93 & 54,37 & 73,64 & 107,00 & 123,95 & 161,87 & 227,54 \\
\hline & 60 & 3,58 & 4,93 & 7,45 & 12,58 & 16,60 & 23,62 & 32,02 & 40,37 & 55,06 & 79,62 & 96,22 & 124,95 \\
\hline & 70 & 1,79 & 2,15 & 2,79 & 6,87 & 8,10 & 10,11 & 19,50 & 22,23 & 26,81 & 53,31 & 59,22 & 68,65 \\
\hline & 80 & 0,97 & 1,02 & 1,10 & 3,95 & 4,13 & 4,47 & 12,34 & 12,80 & 13,47 & 36,70 & 37,88 & 39,39 \\
\hline & 90 & 0,56 & 0,53 & 0,49 & 2,36 & 2,24 & 2,08 & 7,98 & 7,64 & 7,18 & 25,49 & 24,61 & 23,41 \\
\hline \multirow{5}{*}{0,2} & 50 & 4,48 & 6,44 & 10,03 & 15,10 & 20,54 & 30,17 & 36,78 & 48,21 & 67,87 & 87,53 & 109,96 & 149,16 \\
\hline & 60 & 2,25 & 2,88 & 4,06 & 8,33 & 10,34 & 13,85 & 22,51 & 26,86 & 34,32 & 58,98 & 68,07 & 83,09 \\
\hline & 70 & 1,20 & 1,34 & 1,54 & 4,76 & 5,27 & 6,01 & 14,27 & 15,40 & 17,34 & 40,83 & 43,54 & 47,50 \\
\hline & 80 & 0,69 & 0,68 & 0,67 & 2,88 & 2,86 & 2,80 & 9,36 & 9,32 & 9,19 & 29,05 & 28,74 & 28,63 \\
\hline & 90 & 0,41 & 0,37 & 0,32 & 1,77 & 1,60 & 1,41 & 6,21 & 5,71 & 5,10 & 20,57 & 19,21 & 17,47 \\
\hline
\end{tabular}

$\left(\gamma \mathrm{H} / \sigma_{\mathrm{c}}=0.02, \alpha=0, \mathrm{q}=0\right.$ and $\left.\mathrm{D}=0\right)$

\section{Conclusion}

The seismic and static stability of homogeneous and isotropic rock slopes have been studied using the kinematic approach of the yield design theory combined with the pseudo-static method. The strength of the rock is supposed to obey the general Hoek-Brown failure criterion. The use of this approach retains the advantages of the limit analysis and avoids the use of the called tangential methods used to circumvent the difficulty encountered in the calculation of the external work rate and the rate of energy dissipation in the case of a nonlinear criterion.

The relevance of the approach has been proved by comparing the results with those published in the literature. Numerical simulations have been carried out to study the influence of some parameters on slope stability.

\section{References}

1. Chen W-F., Limit Analysis and Soil Plasticity, 638 (1975).

2. Michalowski RL., Geotechnique, 45, 11 (1995).

3. Michalowski RL., J Geotech Geoen. Eng , 128, 5 (2002).

4. Sloan SW., Int J Numer Anal Methods Geomech, 13, 19 (1989).

5. Zhang X. Géotechnique, 49, 8 (1999).

6. Goodman RE. Introduction to Rock Mechanics, 2nd ed. (1989).

7. Hoek E, Bray JD. Rock Slope Engineering, Third Edition. (1981).

8. Jaeger JC. Géotechnique, 21, 37 (1971).

9. Barton N., Eng Geol, 7, 46 (1973).

10. Bieniawski ZT., J South Afr Inst Min Metall, 74, 9 (1974).
11. Hobbs DW., Int J Rock Mech Min Sci Geomech Abstr, 3, 32 (1966).

12. Hoek E., J South Afr Inst Min Metall, 64, 18 (1964).

13. Hoek E., Rock Mech Eng Pract, 26 (1968).

14. Ladanyi B, Archambault G. American Rock Mechanics Association, (1969).

15. Zhang XJ, Chen WF., Int J Numer Anal Methods Geomech, 11, 18 (1987).

16. Hoek E., Brown E.T. Underground Excavations in Rock. (1980).

17. Hoek E., Géotechnique, 33, 37 (1983).

18. Collins IF, Gunn CIM, Pender MJ, Yan W., Int J Numer Anal Methods Geomech, 12, 18 (1988).

19. Drescher A, Christopoulos C., Int J Numer Anal Methods Geomech, 12, 5 (1988).

20. Yang X-L, Li L, Yin J-H., Int J Numer Anal Methods Geomech, 28, 10 (2004).

21. Yang X-L, Li L, Yin J-H. Géotechnique, 54, 7 (2004).

22. R. Richards, D. G. Elms, M. Budhu., J Geotech Eng, 119, 13 (1993).

23. Saada Z, Maghous S, Garnier D., Int J Numer Anal Methods Geomech, 35, 25 (2011).

24. Saada Z, Maghous S, Garnier D., Int J Numer Anal Methods Geomech, 37, 19 (2013).

25. Soubra A-H., J Geotech Geoenvironmental Eng, 125, 10 (1999).

26. Seed HB. Géotechnique, 29, 49 (1979).

27. Hoek, E., Carranza-Torres, C., Corkum, B., NARMS-TAC, 7 (2002).

28. De Buhan P. Plasticité et calcul à la rupture, (2007).

29. Salençon J. Calcul à la rupture et analyse limite, (1983).

30. Salençon J. Yield Design: A Survey of the Theory, 45 (1993).

31. Hoek E. , Int J Rock Mech Min Sci Geomech,27,3 (1990).

32. Saada Z, Maghous S, Garnier D., Comput Geotech, 35, 11 (2008).

33. Kovarik J-B., Rev Fr Génie Civil, 4, 45 (2000). 